\title{
Direct reversible decarboxylation from stable organic acids in dimethylformamide solution
}

\author{
Duanyang Kong*, Patrick J. Moon*, Erica K. J. Lui, Odey Bsharat, Rylan J. Lundgren† \\ Department of Chemistry, University of Alberta, Edmonton, Alberta T6G 2G2, Canada. \\ *These authors contributed equally to this work. †Corresponding author. Email: rylan.lundgren@ualberta.ca
}

Many classical and emerging methodologies in organic chemistry rely on $\mathrm{CO}_{2}$ extrusion to generate reactive intermediates for bond-forming events. Synthetic reactions that involve the microscopic reverse, the carboxylation of reactive intermediates, have conventionally been undertaken using very different conditions. We report that chemically stable $\mathrm{C}\left(\mathrm{sp}^{3}\right)$ carboxylates, such as arylacetic acids and malonate half-esters, undergo uncatalyzed reversible decarboxylation in dimethylformamide solution.

Decarboxylation/carboxylation occurs with substrates resistant to protodecarboxylation by Brønsted acids under otherwise identical conditions. Isotopically labeled carboxylic acids can be prepared in high chemical and isotopic yield by simply supplying an atmosphere of ${ }^{13} \mathrm{CO}_{2}$ to carboxylate salts in polar aprotic solvents. An understanding of carboxylate reactivity in solution enables conditions for the trapping of aldehydes, ketones, and $\alpha, \beta$-unsaturated esters.

Decarboxylation is a fundamental step in biochemical processes and synthetic organic chemistry. Fermentation, respiration, and the biosynthesis of many secondary metabolites involve the loss of $\mathrm{CO}_{2}$ from organic acids $(1,2)$. Decarboxylase enzymes accelerate these reactions by stabilizing developing intermediates (typically carbanions) and promoting $\mathrm{CO}_{2}$ diffusion from the active site, thereby enabling otherwise unfeasible decarboxylations to occur under physiological conditions (Fig. 1A) $(3,4)$. Acid substrates lacking strong anion-stabilizing groups adjacent to the reactive carbon center have been construed to be inert toward spontaneous decarboxylation without resorting to thermolysis conditions (Fig. 1B) (5). As a result, synthetic reactions driven by decarboxylation are often carried out using high reaction temperatures (6), added oxidizing agents $(7,8)$, or prior stoichiometric chemical modification of the carboxylate unit (9-12).

Carboxylation reactions, the microscopic reverse of decarboxylations, are equally valuable processes in biology and synthetic chemistry. Despite the possibility of a shared reaction pathway, the biochemical machinery that promotes carboxylation in $\mathrm{CO}_{2}$ fixation pathways operates with a distinct set of substrates and enzymes from those that promote decarboxylation in all but a few cases (13-17). Similarly, synthetic techniques that generate carboxylic acid derivatives from $\mathrm{CO}_{2}$ have tended to apply strongly nucleophilic organometallics and/or in-situ stoichiometric (electro)chemical substrate reduction $(18,19)$.

The potential for the reversibility of decarboxylation/carboxylation mechanisms is largely ignored in reports of synthetic methodologies that rely on these elementary steps. Reports of direct non-enzymatic reversible $\mathrm{CO}_{2}$-exchange of carboxylic acids are restricted to specialized substrate/mediator pairs $(20,21)$. Exchange of carboxylate groups in simple aliphatic acids with $\mathrm{CO}_{2}$ has been documented, but requires heating of neat substrates at $280-400^{\circ} \mathrm{C}(22,23)$. Nonetheless, in the course of our studies on catalytic decarboxylative cross-coupling reactions $(24,25)$, we questioned whether the apparent stability of organic carboxylates could arise from reversible decarboxylation/carboxylation events in solution. Supporting this hypothesis, we observed that certain simple organic acids that are stable toward protodecarboxylation in solution undergo spontaneous incorporation of ${ }^{13} \mathrm{CO}_{2}$ when this heavier isotope is supplied at atmospheric pressure (Fig. 1C).

The potassium salt of arylacetic acid $\mathbf{1}$ exemplifies the reversible decarboxylation/carboxylation behavior of otherwise chemically stable carboxylic acids. A $0.1 \mathrm{M}$ solution of $\mathbf{1}$ in dimethylformamide (DMF) at $20^{\circ} \mathrm{C}$ underwent $\mathrm{CO}_{2}$ exchange when placed under an atmosphere of ${ }^{13} \mathrm{CO}_{2}$. In a reaction where approximately six equivalents of ${ }^{13} \mathrm{CO}_{2}$ were supplied (13 mL of $\mathrm{CO}_{2}$ at $\sim 1$ atm, dissolved $\left[\mathrm{CO}_{2}\right]=0.20 \mathrm{M}$ ), equilibrium between ${ }^{12} \mathrm{C}$ and ${ }^{13} \mathrm{C}$ was achieved in 15 hours (Fig. $1 \mathrm{C}$, red trace). Quantitative recovery of carboxylate $\mathbf{1}$ with $83 \%$ ${ }^{13} \mathrm{C}$-enrichment was possible by acid/base extractive workup. Under similar conditions at $20^{\circ} \mathrm{C}$ with five equivalents of a weak Brønsted acid (MeOH) no protodecarboxylation of $\mathbf{1}$ was observed (Fig. 1C, black trace). These results demonstrate that capture of the putative nucleophilic intermediate generated from $\mathbf{1}$ with dissolved $\mathrm{CO}_{2}$ is significantly more favorable than protonation. The process tolerates up to $0.01 \mathrm{M} \mathrm{H}_{2} \mathrm{O}$ and does not require rigorous exclusion of air (see fig. S2). During the review of this work, isotopic exchange of carboxylate 
groups in cesium arylacetic acid salts with ${ }^{14} \mathrm{C}$-, ${ }^{13} \mathrm{C}$-, and ${ }^{11} \mathrm{C}$ labeled $\mathrm{CO}_{2}$ in DMSO at $80-190^{\circ} \mathrm{C}$ was reported (26).

The counter-cation of the carboxylate salt impacts carboxylate exchange reactivity (Fig. 1D). The carboxylic acid of $\mathbf{1}$ manifested no evident ${ }^{13} \mathrm{CO}_{2}$ exchange or protodecarboxylation in $\mathrm{DMF}$ at $70^{\circ} \mathrm{C}$. $\mathrm{Li}^{+}$and $\mathrm{Na}^{+}$salts of $\mathbf{1}$ reacted more slowly, while the $\mathrm{Cs}^{+}$salt reacted more quickly. Divalent metal salts of $\mathbf{1}\left(\mathrm{Zn}^{2+}\right.$ or $\left.\mathrm{Cu}^{2+}\right)$ were inert and the addition of $\mathrm{M}^{2+} \mathrm{Cl}_{2}$ salts completely inhibited the reaction $\left(\mathrm{MgCl}_{2}, \mathrm{CaCl}_{2}\right.$, $\mathrm{MnCl}_{2}$, see fig. S3). The use of polar aprotic solvents (DMF, DMA, DMSO; dielectric constant $\varepsilon>30$ ) is essential for the transformation: reactions conducted in THF, DCE, or water resulted in recovery of unlabeled $\mathbf{1}$ at $20^{\circ} \mathrm{C}$. The addition of 18-crown-6 (18-C-6) led to an approximate two-fold rate enhancement of carboxylate exchange (see fig. S4) (27). The free acid underwent carboxylate exchange when 1.5 equivalents of $\mathrm{K}_{2} \mathrm{CO}_{3}$ and $18-\mathrm{C}-6$ were added ( $>90 \%$ yield and ${ }^{13} \mathrm{C}$ incorporation in 19 hours). Collectively, these observations suggest that the generation of a solvent-separated ion pair leads to enhanced decarboxylative reactivity.

Reversible decarboxylation occurred for an array of carboxylate containing molecules that contain adjacent aryl, carbonyl, cyano, or sulfonyl groups, including valuable synthetic precursors, drug molecules, and amino acid derivatives (Fig. 2 ). The incorporation of ${ }^{13} \mathrm{CO}_{2}$ and product recovery remained high $(>80 \%)$ across several substrate classes. The degree of incorporation is largely a function of the amount of ${ }^{13} \mathrm{CO}_{2}$ supplied: $>95 \%$ enrichment can be obtained when $\sim 50$ equivalents is provided (see fig. S5). For successful cases, this carboxylate exchange process compares favorably in terms of operational simplicity to current state-of-the-art methods to prepare $\mathrm{C}\left(\mathrm{sp}^{3}\right){ }^{13 / 14} \mathrm{CO}_{2}$ labeled carboxylic acid-derivatives sought after in (pre)clinical absorption, distribution, metabolism, and excretion (ADME) studies (28). Reported approaches require either chemical activation-decarboxylationmetalation-carboxylation sequences mediated by transition metals (29-31), indirect nucleophilic substitution reactions with labeled cyanide followed by hydrolysis (32), or introduction of labeled carbon monoxide in place of $\mathrm{CO}_{2}(33,34)$. The direct exchange of $\mathrm{C}\left(\mathrm{sp}^{2}\right)$-carboxylate groups catalyzed by transition metals has been demonstrated; however, reactivity is restricted to nitro- or sulfonyl-containing arenes or 2-heteroatom substituted electron-rich heterocycles at high temperature $\left(\geq 150^{\circ} \mathrm{C}\right)(35)$.

(Hetero)arylacetic acid salts with anion-stabilizing groups underwent exchange at moderate temperatures (Fig. 2, 1-4, 9, 10, 11-15 at 20 to $80^{\circ} \mathrm{C}$ ), whereas arylacetates with strongly electron-donating $\mathrm{OMe}$ or $\mathrm{NMe}_{2}$ groups required higher temperatures $\left(\mathbf{1 7 - 2 0}\right.$ at 100 to $130^{\circ} \mathrm{C}$ ) and benefitted from the addition of 18-C-6. The simplicity of the process enabled broad functional group compatibility, including tolerance to boronic esters $(\mathbf{6})$, aryl halides (I, $\mathrm{Br}, \mathrm{Cl}, \mathrm{F} ; \mathbf{4}, \mathbf{7}, \mathbf{8}$,
10), ketones (11), aldehydes (12), esters (14), amides (13), sulfonyls (15), and potentially reactive heterocycles (chromenone 25, NH-indole 26, pyridines $\mathbf{2 7}, \mathbf{2 9}$, pyrimidine 28, isoxazole 30, thiophene 31). Alkyl and aryl substitution adjacent to the carboxylate was tolerated, including examples of trisubstituted, non-enolizable arylacetic acid salts $(\mathbf{2 3}, \mathbf{2 4})$. Other classes of potassium carboxylates that underwent reversible decarboxylation include malonate half-esters (32$\mathbf{3 5})$, keto acids (36), $\beta$-carboxysulfonyls $(\mathbf{3 7}, \mathbf{3 8})$, cyanoacetates (39), and carboxylactams (40). Alkene and terminal alkyne functional groups did not interfere with the process (34, 35). Potassium malonates underwent $\mathrm{CO}_{2}$ exchange at higher temperature $\left(135^{\circ} \mathrm{C}\right)$ to give a mixture of mono- and doublylabeled product along with ${ }^{13} \mathrm{C}$-enriched monoacid $(\mathbf{4 1}, \mathbf{4 2})$.

Carboxylate exchange could also be used to directly prepare isotopically labeled drug molecules, including arylacetic acid salts and propionate NSAIDs of varying complexity (4352, Fig. 2). Pharmaceuticals featuring amide or ester groups were obtained via derivatization of the acid group (Zolpidem 53, Aprofene 55) or could be prepared according to established literature protocols (Propiverine 54, Netupitant 56, Repaglinide 57). Consistent with the generation of a carbanion, racemization of enantiopure Naproxen (46) was observed (fig. S6). Reversible decarboxylation may explain reports of aryl propionate racemization required for kinetic resolution manufacturing processes $(36,37)$. Simple alkyl carboxylates did not undergo $\mathrm{CO}_{2}$ exchange; however isotopically labeled products of this class can be readily obtained by carboxylate exchange/desulfonylation reactions of $\beta$-sulfonyl acids or exchange/decarboxylation sequences of malonic acids in three steps (58-60). The facile generation of ${ }^{13} \mathrm{C}$-diphenylmethylidene glycine at room temperature (61 93\% incorporation, $76 \%$ yield) serves as a starting point for the synthesis of other labeled amino acids (38).

The reversible $\mathrm{CO}_{2}$ exchange process likely involves the formation of a carbon nucleophile either from direct decarboxylation, or potentially in the case of enolizable substrates, through an enolate intermediate. The reaction rates and required temperatures for ${ }^{12} \mathrm{CO}_{2} /{ }^{13} \mathrm{CO}_{2}$ interconversion correlate with the substrate's capacity to stabilize negative charge and not with oxidation potential (compare 1, 14, 16, and 17). The addition of radical inhibitors (TEMPO, BHT) had no impact on the decarboxylative reactivity of $\mathbf{1}$ nor was cyclization of the pendant olefin in $\mathbf{3 4}$ detected.

Exchange of $\mathrm{CO}_{2}$ via carbanion equivalents without competing quenching by other electrophiles (ketones, aldehydes, weak Brønsted acids) likely stems in part from the relatively high solubility of $\mathrm{CO}_{2}$ in DMF and the slow kinetics of $\mathrm{CO}_{2}$ evaporation into the reaction vessel headspace. For example, a $0.25 \mathrm{M}$ solution of ${ }^{13} \mathrm{CO}_{2}$ in DMF retains a concentration of $0.2 \mathrm{M}$ under a headspace of $\mathrm{N}_{2}$ over one day (measured by ${ }^{13} \mathrm{C}$ NMR). For substrate $\mathbf{1}$ the rate of $\mathrm{CO}_{2}$ exchange at $70^{\circ} \mathrm{C}$ was 
$\sim 10$-fold faster than for reaction with benzaldehyde. Perhaps counterintuitively, the rate of protodecarboxylation by weak Brønsted acids is inversely related to acidity (Fig. 3A, in order of decreasing rate of protonolysis: piperidine, aniline, methanol, phenol; see fig. S7 for details). This observation could be attributed to the relative capacity of these species to act as nucleophiles to sequester the liberated $\mathrm{CO}_{2}$. Trapping of $\mathrm{CO}_{2}$ prevents back reaction of the carbanion to the carboxylate leading to an increase in the observed rate of protodecarboxylation.

At $70^{\circ} \mathrm{C}$ under $\mathrm{N}_{2}, \mathbf{1}$ underwent slow net carboxylate/proton metathesis to generate a half equivalent of the protodecarboxylated product 62 and a half equivalent of the $\mathrm{CO}_{2-}$ trapped malonate 63 (Fig. 3B). Product 62 likely arises from deprotonation of a second equivalent of aryl acetate to generate a dienolate nucleophile. The dienolate intermediate can react with the $\mathrm{CO}_{2}$ released by the initial decarboxylation event. This observation demonstrates the striking efficiency of $\mathrm{CO}_{2}$ capture by carbon nucleophiles under suitable conditions. Alkyl arenes generated by protodecarboxylation does not convert back to the carboxylate under the conditions where carboxylate exchange is observed (Fig. 3C). Carbonic anhydride intermediates are likely generated under the reaction conditions on the basis of the observed increase in $\alpha$ carboxyl H/D exchange rates with $\mathbf{1}-\mathbf{H}_{\mathbf{2}}$ and $\mathbf{1}-\mathbf{D}_{\mathbf{2}}$ under $\mathrm{CO}_{2}$ (Fig. 3D, see fig. S9 for details). The generation of a dienolate from the more acidic potassium carbonic anhydride may explain these reactivity differences. Direct detection of anhydride intermediates was not achieved. The capacity of nonenolizable carboxylates, such as $\mathbf{2 3}$ and $\mathbf{2 4}$, to undergo reversible decarboxylation indicates that dienolate or enol intermediates are not essential for carboxylate exchange.

Finally, with an understanding of the factors that contribute to transient substrate decarboxylation, conditions were identified that allowed for the direct decarboxylative trapping of alternative classes of electrophiles (Fig. 3E). Carboncarbon bond forming reactions by the trapping of aldehydes (64-69), a trifluoromethyl ketone (70), and an $\alpha, \beta$-unsaturated ester (71) occurred in reasonable yields under conditions similar to those for reversible decarboxylation. The rates of product formation in aldehyde trapping experiments correlate with substrate electrophilicity. In some cases, it was beneficial (but not essential) to add 18-C-6 to improve decarboxylative reactivity or aniline to sequester liberated $\mathrm{CO}_{2}$ (see SM for complete details). H/D-exchange followed by deuterodecarboxylation provides a simple approach to prepare $\mathrm{CD}_{3}$ labeled toluenes and heterocycles from $\mathrm{D}_{2} \mathrm{O}(\mathbf{7 2}-\mathbf{7 5})$.

Efficient reversible decarboxylation/carboxylation masks the inherent reactivity of otherwise stable carboxylates. An appreciation of this phenomenon enables simple, direct protocols for isotopic exchange of carboxylic acids with ${ }^{13} \mathrm{CO}_{2}$ and methods for decarboxylative carbon-carbon bond forming reactions. The potential for reversible decarboxylation should be considered more generally when designing and executing decarboxylative functionalization processes.

\section{REFERENCES AND NOTES}

1. T. Li, L. Huo, C. Pulley, A. Liu, Decarboxylation mechanisms in biological system. Bioorg. Chem. 43, 2-14 (2012). doi:10.1016/i.bioorg.2012.03.001 Medline

2. P. A. Frey, A. D. Hegeman, Enzymatic Reaction Mechanisms (Oxford Univ. Press, 2007).

3. M. H. O'Leary, in The Enzymes, D. S. Sigman, Ed. (Academic Press, 1992), vol. 20, pp. 235-269.

4. R. Kluger, Decarboxylation, $\mathrm{CO}_{2}$ and the reversion problem. Acc. Chem. Res. 48, 2843-2849 (2015). doi:10.1021/acs.accounts. 5 b00306 Medline

5. A. J. Colussi, V. T. Amorebieta, M. A. Grela, Very low pressure pyrolysis of phenylacetic acid. J. Chem. Soc., Faraday Trans. 88, 2125-2127 (1992). doi:10.1039/ft9928802125

6. N. Rodríguez, L. J. Goossen, Decarboxylative coupling reactions: A modern strategy for C-C-bond formation. Chem. Soc. Rev. 40, 5030-5048 (2011) doi:10.1039/c1cs15093f Medline

7. A. K. Vijh, B. E. Conway, Electrode kinetic aspects of the Kolbe reaction. Chem. Rev. 67, 623-664 (1967). doi:10.1021/cr60250a003

8. Z. W. Zuo, D. T. Ahneman, L. Chu, J. A. Terrett, A. G. Doyle, D. W. C. MacMillan, Merging photoredox with nickel catalysis: Coupling of $\alpha$-carboxyl $\mathrm{sp}^{3}$-carbons with aryl halides. Science 345, 437-440 (2014). doi:10.1126/science.1255525 Medline

9. D. H. R. Barton, S. D. Gero, B. Quiclet-Sire, M. Samadi, N. Ozbalik, J. C. Sarma, M. Ramesh, New reactions for use in natural products chemistry. Pure Appl. Chem. 60, 1549-1554 (1988). doi:10.1351/pac198860111549

10. T. Qin, J. Cornella, C. Li, L. R. Malins, J. T. Edwards, S. Kawamura, B. D. Maxwell, M. D. Eastgate, P. S. Baran, A general alkyl-alkyl cross-coupling enabled by redoxactive esters and alkylzinc reagents. Science 352, 801-805 (2016) doi:10.1126/science.aaf6123 Medline

11. M. B. Smith, March's Advanced Organic Chemistry - Reactions, Mechanisms, and Structure (Wiley, ed. 7, 2013).

12. J. Schwarz, B. Konig, Decarboxylative reactions with and without light - a comparison. Green Chem. 20, 323-361 (2018). doi:10.1039/C7GC02949G

13. R. B. Silverman, Ed., Organic Chemistry of Enzyme-Catalyzed Reactions (Academic Press, ed. 2, 2002), pp. 289-320.

14. S. S. Bailey, K. A. P. Payne, A. Saaret, S. A. Marshall, I. Gostimskaya, I. Kosov, K. Fisher, S. Hay, D. Leys, Enzymatic control of cycloadduct conformation ensures reversible 1,3-dipolar cycloaddition in a prFMN-dependent decarboxylase. Nat. Chem. 11, 1049-1057 (2019). doi:10.1038/s41557-019-0324-8 Medline

15. T. Nunoura, Y. Chikaraishi, R. Izaki, T. Suwa, T. Sato, T. Harada, K. Mori, Y. Kato, M. Miyazaki, S. Shimamura, K. Yanagawa, A. Shuto, N. Ohkouchi, N. Fujita, Y. Takaki, H. Atomi, K. Takai, A primordial and reversible TCA cycle in a facultatively chemolithoautotrophic thermophile. Science 359, 559-563 (2018). doi:10.1126/science.aao3407 Medline

16. A. Mall, J. Sobotta, C. Huber, C. Tschirner, S. Kowarschik, K. Bačnik, M. Mergelsberg, M. Boll, M. Hügler, W. Eisenreich, I. A. Berg, Reversibility of citrate synthase allows autotrophic growth of a thermophilic bacterium. Science 359 , 563-567 (2018). doi:10.1126/science.aao2410 Medline

17. X. Sheng, Y. Patskovsky, A. Vladimirova, J. B. Bonanno, S. C. Almo, F. Himo, F. M. Raushel, Mechanism and structure of $\gamma$-resorcylate decarboxylase. Biochemistry 57, 3167-3175 (2018). doi:10.1021/acs.biochem.7b01213 Medline

18. Q. Liu, L. Wu, R. Jackstell, M. Beller, Using carbon dioxide as a building block in organic synthesis. Nat. Commun. 6, 5933 (2015). doi:10.1038/ncomms6933 Medline

19. A. Tortajada, F. Juliá-Hernández, M. Börjesson, T. Moragas, R. Martin, Transitionmetal-catalyzed carboxylation reactions with carbon dioxide. Angew. Chem. Int Ed. 57, 15948-15982 (2018). doi:10.1002/anie.201803186 Medline

20. D. J. Darensbourg, E. M. Longridge, M. W. Holtcamp, K. K. Klausmeyer, J. H. Reibenspies, Reversible decarboxylation of phosphine derivatives of $\mathrm{Cu}(\mathrm{I})$ cyanoacetate. Mechanistic aspects germane to catalytic decarboxylation of carboxylic acids. J. Am. Chem. Soc. 115, 8839-8840 (1993) doi:10.1021/ja00072a047

21. A. Häussermann, F. Rominger, B. F. Straub, $\mathrm{CO}_{2}$ on a tightrope: Stabilization, room- 
temperature decarboxylation, and sodium-induced carboxylate migration. Chemistry 18, 14174-14185 (2012). doi:10.1002/chem.201202298 Medline

22. A. Szabolcs, J. Szammer, L. Noszkó, A new method for the preparation of carboxyllabelled aliphatic carboxylic acids. Tetrahedron 30, 3647-3648 (1974). doi:10.1016/S0040-4020(01)97049-8

23. R. Nakai, M. Sugii, H. Nakao, Isotopic tracer studies of the ketonic pyrolysis of sodium carboxylates. J. Am. Chem. Soc. 81, 1003-1006 (1959). doi:10.1021/ja01513a061

24. P. J. Moon, S. Yin, R. J. Lundgren, Ambient decarboxylative arylation of malonate half-esters via oxidative catalysis. J. Am. Chem. Soc. 138, 13826-13829 (2016). doi:10.1021/jacs.6b08906 Medline

25. P. J. Moon, A. Fahandej-Sadi, W. Qian, R. J. Lundgren, Decarboxylative benzylation of aryl and alkenyl boronic esters. Angew. Chem. Int. Ed. 57, 4612-4616 (2018). doi:10.1002/anie.201800829 Medline

26. G. Destro, K. Horkka, O. Loreau, D. A. Buisson, L. Kingston, A. Del Vecchio, M. Schou, C. S. Elmore, F. Taran, T. Cantat, D. Audisio, Transition-metal-free carbon isotope exchange of phenyl acetic acids. Angew. Chem. Int. Ed. (2020). 10.1002/anie.202002341 Medline

27. D. H. Hunter, M. Hamity, V. Patel, R. A. Perry, Crown ether catalysis of decarboxylation: A general survey of reactivity and detailed analysis of the triphenylacetate anion. Can. J. Chem. 56, 104-113 (1978). doi:10.1139/v78-017

28. C. S. Elmore, R. A. Bragg, Isotope chemistry; a useful tool in the drug discovery arsenal. Bioorg. Med. Chem. Lett. 25, 167-171 (2015). doi:10.1016/i.bmcl.2014.11.051 Medline

29. K. Hinsinger, G. Pieters, The emergence of carbon isotope exchange. Angew. Chem. Int. Ed. 58, 9678-9680 (2019). doi:10.1002/anie.201905368 Medline

30. C. Kingston, M. A. Wallace, A. J. Allentoff, J. N. deGruyter, J. S. Chen, S. X. Gong, S. Bonacorsi Jr., P. S. Baran, Direct carbon isotope exchange through decarboxylative carboxylation. J. Am. Chem. Soc. 141, 774-779 (2019). doi:10.1021/jacs.8b12035 Medline

31. A. Tortajada, Y. Duan, B. Sahoo, F. Cong, G. Toupalas, A. Sallustrau, O. Loreau, D. Audisio, R. Martin, Catalytic decarboxylation/carboxylation platform for accessing isotopically labeled carboxylic acids. ACS Catal. 9, 5897-5901 (2019). doi:10.1021/acscatal.9b01921

32. R. Voges, J. R. Heyes, T. Moenius, Preparation of Compounds Labeled with Tritium and Carbon-14 (Wiley, 2009).

33. D. U. Nielsen, K. T. Neumann, A. T. Lindhardt, T. Skrydstrup, Recent developments in carbonylation chemistry using $\left[{ }^{13} \mathrm{C}\right] \mathrm{CO},\left[{ }^{11} \mathrm{C}\right] \mathrm{CO}$, and $\left[{ }^{14} \mathrm{C}\right] \mathrm{CO}$. J. Labelled Comp. Radiopharm. 61, 949-987 (2018). doi:10.1002/jلcr.3645 Medline

34. D. R. Gauthier Jr., N. R. Rivera, H. Yang, D. M. Schultz, C. S. Shultz, Palladiumcatalyzed carbon isotope exchange on aliphatic and benzoic acid chlorides. J. Am. Chem. Soc. 140, 15596-15600 (2018). doi:10.1021/jacs.8b09808 Medline

35. G. Destro, O. Loreau, E. Marcon, F. Taran, T. Cantat, D. Audisio, Dynamic carbon isotope exchange of pharmaceuticals with labeled $\mathrm{CO}_{2}$. J. Am. Chem. Soc. 141 , 780-784 (2019). doi:10.1021/jacs.8b12140 Medline

36. I. Shiina, K. Ono, K. Nakata, Non-enzymatic dynamic kinetic resolution of racemic $\alpha$-arylalkanoic acids: An advanced asymmetric synthesis of chiral nonsteroidal anti-inflammatory drugs (NSAIDs). Catal. Sci. Technol. 2, 2200-2205 (2012). doi:10.1039/c2cy20329d

37. P. J. Harrington, E. Lodewijk, Twenty years of naproxen technology. Org. Process Res. Dev. 1, 72-76 (1997). doi:10.1021/op960009e

38. T. Ooi, K. Maruoka, Recent advances in asymmetric phase-transfer catalysis. Angew. Chem. Int. Ed. 46, 4222-4266 (2007). doi:10.1002/anie.200601737 Medline

39. W. C. Still, M. Kahn, A. Mitra, Rapid chromatographic technique for preparative separations with moderate resolution. J. Org. Chem. 43, 2923-2925 (1978). doi:10.1021/j000408a041

40. R. Shang, Z.-W. Yang, Y. Wang, S.-L. Zhang, L. Liu, Palladium-catalyzed decarboxylative couplings of 2-(2-azaaryl)acetates with aryl halides and triflates. J. Am. Chem. Soc. 132, 14391-14393 (2010). doi:10.1021/ja107103b Medline

41. J. E. Day, S. Y. Sharp, M. G. Rowlands, W. Aherne, P. Workman, C. J. Moody, Targeting the Hsp90 chaperone: Synthesis of novel resorcylic acid macrolactone inhibitors of Hsp90. Chemistry 16, 2758-2763 (2010). doi:10.1002/chem.200902766 Medline

42. R. Shang, Z. Huang, L. Chu, Y. Fu, L. Liu, Palladium-catalyzed decarboxylative coupling of potassium nitrophenyl acetates with aryl halides. Org. Lett. 13, 42404243 (2011). doi:10.1021/ol201750s Medline

43. T. T. Mai, B. Viswambharan, D. Gori, R. Guillot, J.-V. Naubron, C. Kouklovsky, V. Alezra, Frozen chirality of tertiary aromatic amides: Access to enantioenriched tertiary $\alpha$-amino acid or amino alcohol without chiral reagent. Chemistry 23 . 5787-5798 (2017). doi:10.1002/chem.201700110 Medline

44. P. Borowiecki, P. Wińska, M. Bretner, M. Gizińska, M. Koronkiewicz, M. Staniszewska, Synthesis of novel proxyphylline derivatives with dual anti-Candida albicans and anticancer activity. Eur. J. Med. Chem. 150, 307-333 (2018). doi:10.1016/i.ejmech.2018.02.077 Medline

45. D. J. D. Bon, O. Kováč, V. Ferugová, F. Zálešák, J. Pospiśil, One and two-carbon homologation of primary and secondary alcohols to corresponding carboxylic esters using $\beta$-carbonyl BT sulfones as a common intermediate. J. Org. Chem. 83 , 4990-5001 (2018). doi:10.1021/acs.joc.8b00112 Medline

46. R. Shintani, S. Park, F. Shirozu, M. Murakami, T. Hayashi, Palladium-catalyzed asymmetric decarboxylative lactamization of $\gamma$-methylidene- $\delta$-valerolactones with isocyanates: Conversion of racemic lactones to enantioenriched lactams. J. Am. Chem. Soc. 130, 16174-16175 (2008). doi:10.1021/ja807662b Medline

47. Y. Li, W. Zhang, H. Zhang, W. Tian, L. Wu, S. Wang, M. Zheng, J. Zhang, C. Sun, Z. Deng, Y. Sun, X. Qu, J. Zhou, Structural basis of a broadly selective acyltransferase from the polyketide synthase of splenocin. Angew. Chem. Int. Ed. 57, 5823-5827 (2018). doi:10.1002/anie.201802805 Medline

48. J. Nandi, N. E. Leadbeater, Visible-light-driven catalytic oxidation of aldehydes and alcohols to nitriles by 4 -acetamido-TEMPO using ammonium carbamate as a nitrogen source. Org. Biomol. Chem. 17, 9182-9186 (2019). doi:10.1039/C90B01918A Medline

49. T. Kimachi, H. Nagata, Y. Kobayashi, K. Takahashi, E. Torii, M. Ju-ichi, Regioselective ring-opening reaction of unsymmetrical 2,3-diaryl epoxides via catalytic hydrogenolysis with $\mathrm{Pd}(0) \mathrm{EnCat}^{\mathrm{TM}}$. Synlett 2011, 365-368 (2011). doi:10.1055/s-0030-1259505

\section{ACKNOWLEDGMENTS}

We thank A. Speed for analysis of this manuscript and experimental suggestions. We thank J. Takats for the gift of ${ }^{13} \mathrm{CO}_{2}$ to initiate this project and $\mathrm{B}$. Reiz for assistance in mass spectrometry data analysis. Funding: Support was provided by NSERC Canada (RGPIN-2019-06050, RGPAS-2019-00051) the Canadian Foundation for Innovation (IOF 32691), the University of Alberta, and the Killam Trusts Author contributions: P.J.M. and R.J.L. conceived the study. Experiments and data analysis were conducted by D.K., P.J.M, E.J.K.L, and O.B. The manuscript was written by R.J.L. with consultation from all co-authors. Competing interests: P.J.M. and R.J.L. (University of Alberta) are pursuing a provisional patent on this work. Data and materials availability: All experimental data are available in the supplementary materials.

\section{SUPPLEMENTARY MATERIALS}

science.sciencemag.org/cgi/content/full/science.abb4129/DC1

Materials and Methods

Figs. S1 to S9

HRMS and NMR Spectra

References (39-49)

25 February 2020; accepted 9 June 2020

Published online 18 June 2020

10.1126/science.abb4129 
A enzymatic decarboxylation - facile under physicological conditions

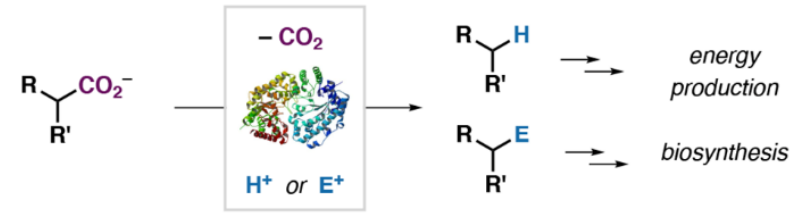

B unactivated carboxylic acids construed to need high temperature to decarboxylate

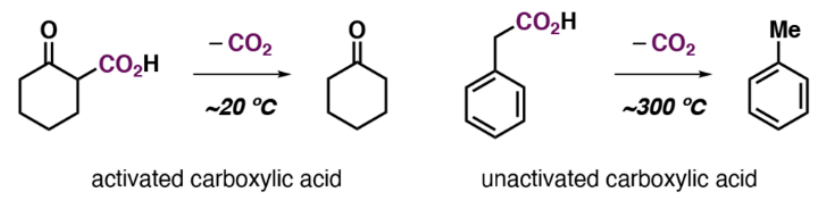

C

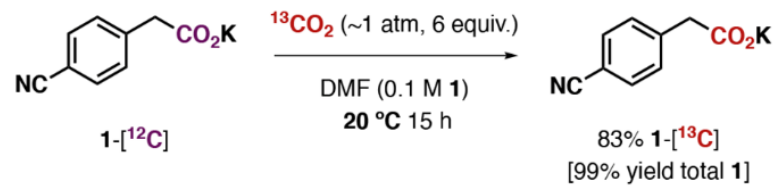

carboxylate 1 mass balance with 5 equiv. $\mathbf{M e O H}:>99 \%$ [no protodecarboxylation]

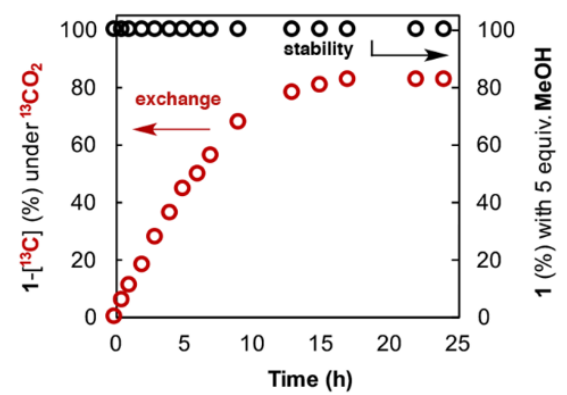

D

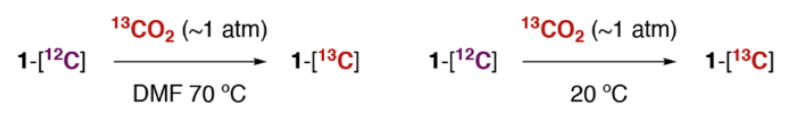

\begin{tabular}{|cc|cc|}
\hline cation & ${ }^{13} \mathrm{C}$ incorp. (time) & conditions & ${ }^{13} \mathrm{C}$ incorp. (time) \\
\hline $\mathrm{K}^{+}$ & $85 \%(1 \mathrm{~h})$ & $\mathrm{THF}$ & $0 \%(5 \mathrm{~h})$ \\
$\mathrm{H}^{+}$ & $<5 \%(8 \mathrm{~h})$ & $\mathrm{DCE}$ & $0 \%(5 \mathrm{~h})$ \\
$\mathrm{Li}^{+}$ & $72 \%(8 \mathrm{~h})$ & $\mathrm{H}_{2} \mathrm{O}$ & $0 \%(5 \mathrm{~h})$ \\
$\mathrm{Na}^{+}$ & $77 \%(8 \mathrm{~h})$ & $\mathrm{DMSO}$ & $47 \%(5 \mathrm{~h})$ \\
$\mathrm{Cs}^{+}$ & $63 \%(5 \mathrm{~h}, \mathrm{rt})$ & $\mathrm{DMA}$ & $45 \%(5 \mathrm{~h})$ \\
$0.5 \mathrm{Zn}^{2+} / \mathrm{Cu}^{2+}$ & $<5 \%(8 \mathrm{~h})$ & $\mathrm{DMF} / 18-\mathrm{C}-6$ & $67 \%(5 \mathrm{~h})$ \\
\hline
\end{tabular}

Fig. 1. Overview of decarboxylative processes and carboxylate exchange. (A) Decarboxylation catalyzed by enzymes under physiological conditions (PDB ID: 2INF). (B) Comparison of conditions used for thermal decarboxylation of different substrates. (C) Comparison of $\mathrm{CO}_{2}$ exchange (red) and protonation with $\mathrm{MeOH}$ (black) for 4-cyanophenylacetate (1). (D) Impact of salt and reaction conditions. $\mathrm{E}^{+}$, electrophile; DMF, dimethylformamide; THF, tetrahydrofuran; DCE, 1,2dichloroethane; DMSO, dimethylsulfoxide; DMA, dimethylacetamide; 18-C-6, 18-crown-6. 


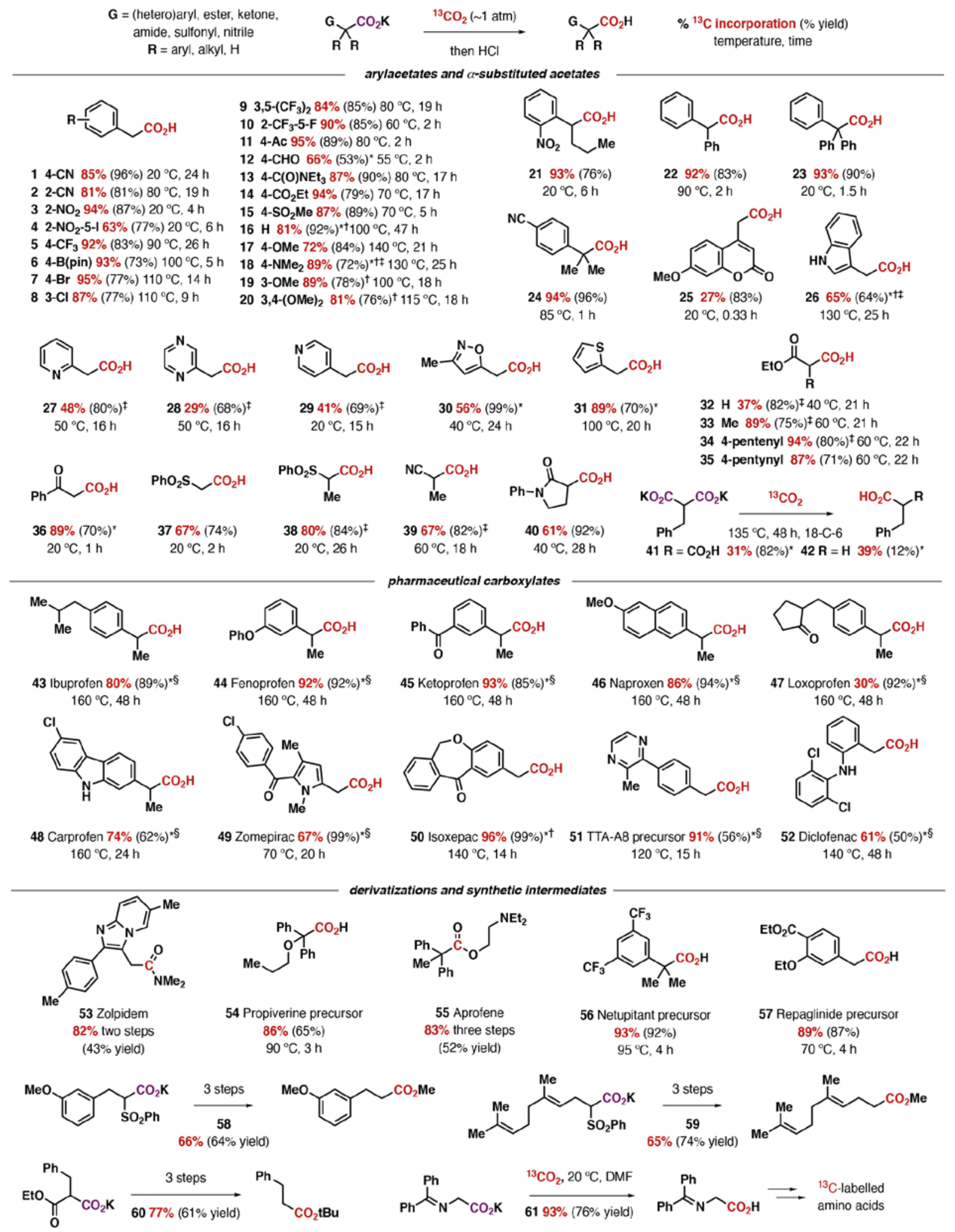

Fig. 2. Carboxylate exchange scope and application. Unless noted yields are of isolated material. ${ }^{*}$ Calibrated ${ }^{1} \mathrm{H}$ NMR spectroscopy yield. $\dagger 1$ Equivalent $18-\mathrm{C}-6$ added. $\ddagger \%{ }^{13} \mathrm{C}$ Incorporation and yield determined by analysis of the corresponding methyl or benzyl ester. § DMSO used instead of DMF. See the supplementary materials for complete details. NMR, nuclear magnetic resonance. 
A relative rates of electrophile trapping and protodecarboxylation

NC

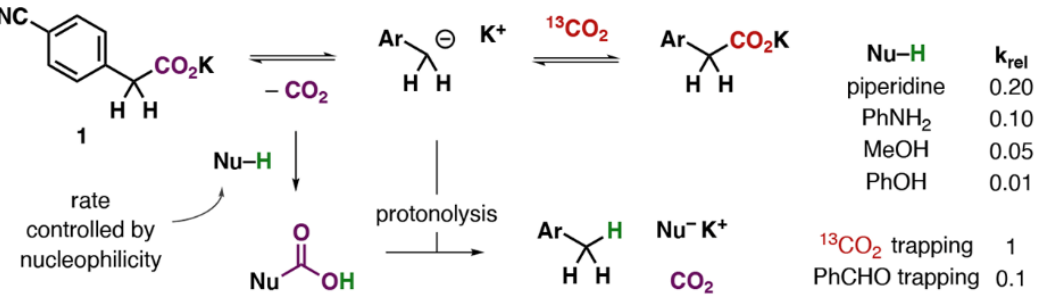

B carboxylate/proton metathesis under $\mathrm{N}_{2}$

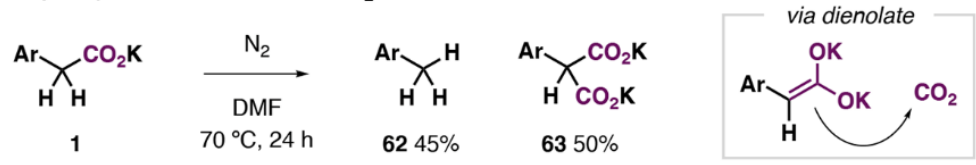

C protodecarboxylation products are not re-carboxylated

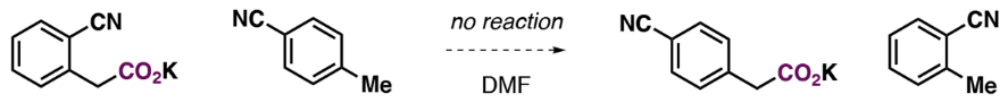

D evidence of anhydride formation: $\mathrm{CO}_{2}$ enhances rate of enolate $\mathrm{H} / \mathrm{D}$ exchange

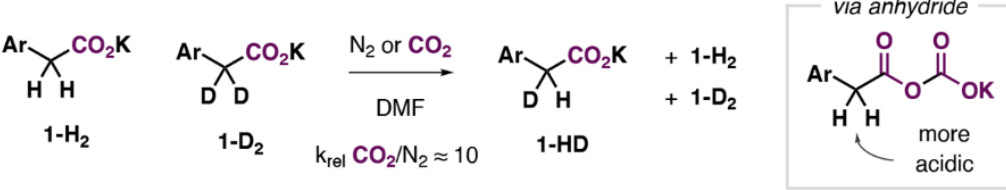

E decarboxylative trapping of other electrophiles

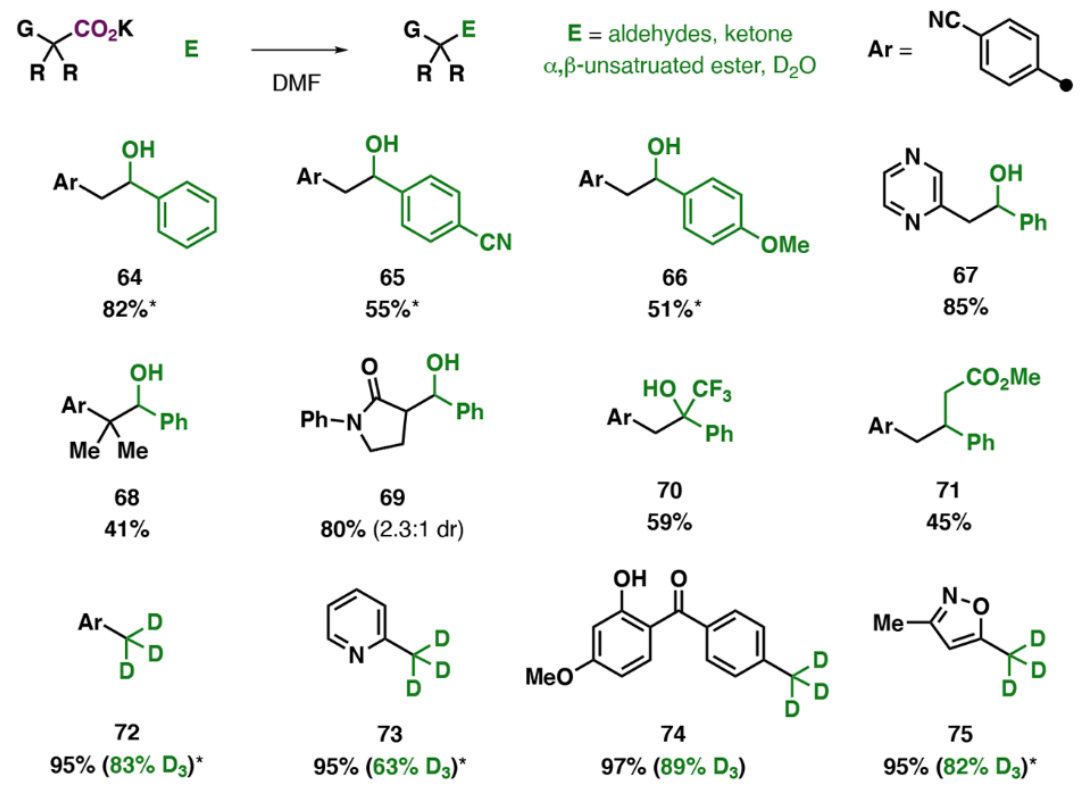

Fig. 3. Mechanistic control experiments and electrophile trapping. (A) Relative rates for arylacetic acid salt protodecarboxylation by Brønsted acids and decarboxylative trapping by benzaldehyde. (B) Net carboxylate/proton metathesis of 1 in the absence of additional $\mathrm{CO}_{2}$. (C) $\mathrm{CO}_{2}$ transfer between arylacetic acid salt and alkylarene does not occur. (D) The presence of $\mathrm{CO}_{2}$ accelerates the rate of methylene $\mathrm{C}-\mathrm{H} / \mathrm{D}$ exchange in 1 . (E) Scope examples for the decarboxylative trapping of alternative classes of electrophiles. See the supplementary materials for complete details and full reaction conditions. ${ }^{*}$ Yield determined by ${ }^{1} \mathrm{H}$ NMR spectroscopy. $\mathrm{Ar},(4-\mathrm{CN}) \mathrm{C}_{6} \mathrm{H}_{4}$. 